\title{
Quatro ambivalências na teoria da comunicação
}

\author{
Luís Mauro Sá Martino \\ Doutor em Ciências Sociais pela PUC-SP. \\ Foi pesquisador-bolsista na Universidade de East Anglia e \\ é autor de Teoria da comunicação e Comunicação e identidade, entre outros.
}

\section{Resumo:}

Este artigo compara o conteúdo de livros intitulados "Teoria da Comunicação" publicados por autores brasileiros nos últimos doze anos a partir de quatro questões: O que é Comunicação? Qual o objeto de estudo da Teoria da Comunicação? Quais os principais métodos? O que é Teoria da Comunicação? O resultado aponta índices mínimos de consenso entre os autores a respeito desses elementos, indicando certa flexibilidade das fronteiras do campo de estudos e, ao mesmo tempo, a valorização de uma perspectiva interdisciplinar na epistemologia da comunicação.

Palavras-chave: Teoria, epistemologia, comunicação.

Abstract: This paper analyses the books named "Communication Theory" trying to identify the common elements from four main questions: what is Communication? What is the study object of Communication Theory? What are the main methods? What is Communication Theory? The results shows that there is little agreement among the authors concerning these questions, what somehow seems to blur the disciplinary boundaries - and this is seen as a good epistemological fact.

Keywords: Theory, epistemology, communication.

De acordo com o Inep, uma das agências do governo responsáveis pela educação superior, existem atualmente em funcionamento 456 cursos de Publicidade e Propaganda, 361 de Jornalismo, 127 de Relações Públicas, 30 de Rádio e TV, 27 de Cinema e 3 de Editoração. Dessa maneira, há pouco espaço para se duvidar de que a Comunicação está, de fato e de direito, vinculada à esfera do ensino superior. Quando se pensa que cada um desses 1004 cursos forme pelo menos de trinta a quarenta alunos por ano - a estimativa é necessária porque o Inep fornece apenas o número de vagas oferecidas em cada universidade, não o de estudantes - temos entre 30 e 40 mil novos profissionais de Comunicação a cada ano no país.

Se é lícito pensar que a idéia de "curso superior" implica em algo mais do que ensinar aos alunos técnicas e fórmulas para escrever ou dizer-lhes qual botão apertar, é possível imaginar que essas 40 mil pessoas tiveram algum tipo de formação teórica na área, e, presumivelmente, cursaram ao menos um semestre da disciplina denominada Teoria da Comunicação.

Há várias perguntas que podem ser feitas a partir desta afirmação. Uma delas, que se tentará delinear não responder - neste texto, é discutir as condições de formação do estatuto epistemológico dessa disciplina, ou antes, desse conjunto de saberes intitulado "Teoria da Comunicação", em um curso que apenas nos anos 1960 encontrou espaço pleno entre os saberes universitários, mesmo no exterior. 
Este texto é seqüência de um estudo prévio a respeito do que se entende por "teoria da comunicação" tal como apresentada nos quinze livros de autores brasileiros que levam esse título (MARTINO, 2008). Analisando as escolas e autores apresentados em cada um, foi possível identificar uma coincidência temática de apenas $23,25 \%$ - ou seja, o consenso sobre o que é "teoria da comunicação" estende-se por menos de um quarto do total de idéias e conceitos que podem ser incluídos nessa disciplina.

Neste texto, utilizando o mesmo corpus da literatura acadêmica, o objetivo é delinear algumas das razões dessa disparidade doutrinária. Esse delineamento passa pela observação de quatro ambivalências da Teoria da Comunicação: o lugar disperso da "teoria" nos cursos de comunicação, a ambivalência doutrinária, a pluralidade dos objetos e os limites do que é "interdisciplinar". No texto, os trechos extraídos do corpus estão com recuo de parágrafo. Para evitar sobreposição e repetições, foram escolhidos os trechos mais representativos para evidenciar cada tema em pauta.

Pertencem ao objeto de estudo desta pesquisa, em ordem de publicação:

Gomes, Pedro. Tópicos de Teoria da Comunicação. São Leopoldo: Ed. Unisinos, 2001 (primeira edição em 1997).

Rüdiger, Francisco. Introdução à Teoria da Comunicação. São Paulo: Edicon, 1998.

Melo, José Marques de. Teoria da Comunicação: Paradigmas Latino-Americanos. Petrópolis: Vozes, 1999.

Polishuk, Ilana e Trinta, Aluízio Ramos. Teorias da Comunicação. Rio de Janeiro: Campus, 2002.

Hohfeldt, Antonio. et alli. Teorias da Comunicação. Petrópolis: Vozes, 2002.

Maldonado, Alberto Efendy. Teoria da comunicação na América Latina, Porto Alegre: Sulina, 2002.

Costa, Rosa Maria et alli. Teoria da Comunicação na América Latina. Curitiba: UFPR, 2006.

Santos, Roberto. As Teorias da Comunicação. São Paulo, 2003.

Martins, Luiz. Teorias da comunicação no século XX. Brasília: Casa das Musas, 2005.

Vilalba, Rodrigo. Teoria da Comunicação. São Paulo: Ática, 2007.

Ferreira, Giovandro. e Martino, Luiz C. Teorias da Comunicação. Salvador: UFBA, 2007.

Martino, Luiz C. (org.) Teorias da Comunicação: muitas ou poucas? Cotia: Ateliê Editorial, 2007.

Vale assinalar que, destes, apenas Teorias da Comunicação (HOHFELDT, FRANÇA \& MARTINO, 2002) comporta um capítulo voltado às questões epistemológicas, enquanto Teorias da Comunicação, de Ferreira e Martino (2007) e Teorias da Comunicação: muitas ou poucas? (MARTINO, 2007) são dedicados exclusivamente a esse debate. Os demais parecem seguir um caminho diferente, no sentido de apresentar as idéias de maneira crítica mais do que dedicar espaço à discussão sobre o que é "teoria da comunicação" - não que esse espaço não exista, mas é consideravelmente menor.

Este texto não tem a pretensão de resolver essas questões, mas propor sua articulação como questões de pesquisa decorrentes da observação empírica das indefinições a respeito do que é "teoria da comunicação". A 
idéia não é observar o campo "de fora”, com a ilusão de objetividade. Ao contrário, é como participante nos mesmos questionamentos que se pretende compreender o que acontece. Entende-se que situar o debate é um caminho para se pensar respostas.

\section{A ambigüidade da teoria nos cursos de comunicação}

Quando se reúne um corpo de doutrinas, métodos, idéias e conceitos sob um mesmo nome, quando esse corpo é elevado ao status de disciplina acadêmica - portanto, ocupando uma posição de destaque em uma instância legítima de reconhecimento simbólico e de consagração intelectual - e a esse corpo se dedicam livros, encontros, grupos de trabalho e de pesquisa, é razoável que se desenvolva uma crença na existência desse corpo, o que implica a formação de um espaço próprio de reflexão e elaboração pensado como um Campo da Comunicação (CRAIG, 1999: 123; LOPES, 2001).

Mas, como questiona Kellner (1995: 163), onde começa/termina a Teoria da Comunicação? A legitimação ocorre pelo procedimento e o processo autoriza-se a si mesmo. A crença na existência de uma disciplina pode ser o resultado tautológico e aceito desse processo de auto-legitimação. Há indicações de que o campo da comunicação tenha passado por um desenvolvimento histórico baseado na ilusão de sua própria existência em termos autônomos, e, assim, a interdisciplinaridade exibida como trunfo epistemológico e instância consagradora de um reconhecimento baseado na singularidade seria apenas uma justificativa para legitimar em uma instância metodologicamente válida essa trajetória histórica (SEVERIN \& TANKARD, 2003: 14).

Um campo do conhecimento define-se não apenas a partir dos objetos e das temáticas que merecem uma reflexão mais profunda, mas sobretudo a partir de olhares e de perguntas que lançamos sobre os fenômenos sociais que, a rigor, perpassam variados campos de saberes (BARBOSA, 2002: 73).

Criados nos Estados Unidos, os cursos de comunicação tinham como tarefa garantir a legitimidade institucional de um tipo de saber digno de ter uma teoria própria (CARLSON, 2007: 223).

Vale acrescentar que os estudos europeus de comunicação se depararam com um problema semelhante ao subordinar a comunicação às condições de uma análise ora política, ora semiótica, mas quase nunca a partir do próprio ato comunicativo e, focando o caso brasileiro, Taschner (1983: 15) aponta a "carência de material didático" nacional nos cursos de comunicação.

Essa ausência, no entanto, parece estar ligada a outra questão, dessa vez de caráter epistemológico:

Qual o 'saber' buscado e construído por nós, pesquisadores da comunicação? Se as práticas comunicativas permeiam as múltiplas dimensões da vida social e atravessam todas as demais práticas, e nosso objeto de estudo diz respeito - e é indagado - por inúmeros outros campos de conhecimento 
dentro do vasto espectro das ciências sociais e das humanidades, qual é a especificidade de um possível saber ou uma abordagem comunicacional dos fenômenos? (FRANÇA, 2004: 13).

Venício Lima (1991:160) aponta "uma relação inversa entre a expansão institucional da área e o desenvolvimento teórico. A comunicação passou a ser entendida e definida em termos das profissões e do espaço institucional que ocupa nas universidades e não de forma teórico-conceitual". Em outro texto (LIMA, 1983: 86), o mesmo pesquisador destaca que a formação teórica em comunicação teve seu início a partir da aglutinação ao redor de práticas profissionais, de um lado, e necessidades políticas de controle sobre essa categoria profissional, de outro.

Dessa maneira, a pesquisa em comunicação, motivada por questões profissionais ou políticas, desenvolveu-se rápida e desordenadamente, sem tempo para a constituição de um corpo teórico e doutrinário específico.

A observação da teoria da comunicação de matriz anglo-saxônica mostra a inexistência de problemas na constituição do objeto. A investigação é dividida em áreas, cada uma delas caudatária de uma ciência específica, e isso resolve o problema epistemológico. A delimitação rigorosa do objeto, a obtenção e análise de dados universalmente observáveis e empiricamente controláveis, a experiência de laboratório para testar hipóteses, o estreitamento necessário do universo em discussão e a fragmentação do saber foram as características fundadoras do campo de investigação em comunicação e assim permanecem até hoje (DAHLGREN, 2004). Os periódicos que divulgam os dados desse tipo de ciência são cheios de tabelas, gráficos, detalhadas descrições do objeto e resultados derivados de investigações tão minuciosas quanto restritas em abrangência.

Assim, a comunicação interpessoal é geralmente reservada aos estudos de psicologia e teoria do comportamento, enquanto as pesquisas na Mass Communication Research são elaboradas por sociólogos ou, em alguns casos, psicólogos sociais (BLUMER, 1978; HABERMAS, 1976: 133; MERTON, 1957: 439; HEISLER \& DISCENA, 2001: 149; CHAFEE et alli, 1990). Esse modelo anglo-saxão, inicialmente aplicado no Brasil, encontrou uma situação dupla: cursos de comunicação organizados no cruzamento de uma matriz prática norte-americana acompanhada de uma crítica européia.

No mesmo sentido, Alberto Efendy Maldonado (2004: 42) aponta a existência de um paradoxo entre o crescimento das pesquisas em comunicação na América Latina a partir dos anos 80 e o pouco desenvolvimento no debate das questões epistemológicas, teóricas e metodológicas. O autor credita isso à complexidade das temáticas, à pouca tradição de pesquisa científica da área e à atitude dos cientistas sociais de considerar o campo como "pouco merecedor" de preocupações epistemológicas. 
Alguns dos próprios livros intitulados Teoria da Comunicação questionam essa ambiguidade: “A comunicação constitui valorativamente um tema de importância consensual, cujo conteúdo no entanto está longe de ter sido esclarecido quando se passa à sua definição teórica” (RÜDIGER, 1998: 10).

Melo (1999: 12) credita esse desenvolvimento multidisciplinar a dois fatores. De um lado, a “contingência temporal, ou seja, a indisponibilidade de massa crítica suficiente de comunicólogos ou midiólogos no Brasil” e, por outro, à "reprodução de experiências que já haviam sido testadas em outras quadraturas com resultados satisfatórios".

É preciso, desde logo, advertir para o fato de que o campo da comunicação é difuso quanto à sua natureza epistemológica. Tanto pode ser recortado enquanto campo científico (ciências sociais aplicadas) quanto pode ser encarado como um conjunto de segmentos prático-corporativos, composto por profissionais de comunicação (jornalistas, radialistas, publicitários, relações públicas, cineastas, apresentadores, produtores, etc.), ou ainda como um campo do 'saber político' das instituições direta ou indiretamente implicadas na gestão ou no controle dos mass media (MARTINS, 2005: 5).

Essa indefinição epistemológica se reflete na composição curricular dos cursos de comunicação e na razão de ser de sua existência. Desprovido das fronteiras da tradição que por vezes funcionam como garantia de legitimidade, o campo da Comunicação é alvo constante de dúvidas sobre a necessidade de sua existência a infindável querela sobre a necessidade do diploma para as habilitações é uma de suas faces visíveis. "Daí a situação extremamente sui generis da Comunicação como um campo bem desenvolvido no lado institucional sem nada dever às teorias mais desenvolvidas, salvo uma única coisa: as teorias” (MARTINO, 2007: 39).

\section{A indefinição doutrinária}

A existência de um corpo de conhecimentos próprio parece ser uma das premissas de legitimidade de um campo de estudos. Empiricamente é possível notar que a maior parte dos trabalhos clássicos usados como "teoria da comunicação" foi escrito por pessoas oriundas de outros campos. A produção de textos sobre comunicação, portanto, é subsidiária de métodos, teorias e conceitos de outros campos de conhecimento. Em estudo sobre os últimos cinqüenta anos de pesquisa em Comunicação nos Estados Unidos, Bryant e Miron (2004: 665) constatam, com ampla base empírica, que "uma considerável porção das teorias da comunicação utilizadas na pesquisa são derivadas da psicologia e da sociologia, com importantes contribuições do direito e da política". Aos olhos do crítico, esse tipo de definição mostra uma contradição nos termos, a saber, a enunciação da ambivalência do campo ocorre em sua própria definição.

Essa ambivalência está presente quase que como condição fundante do campo da comunicação.

A partir de muitas posições intelectuais, ideológicas e geográficas, a multiplicação de propostas de reformulação teórica e prática dos estudos de comunicação manifesta uma insatisfação generalizada com o estado atual do campo e a urgência de repensar seus fundamentos e reorientar seu exercício (FUENTES NAVARRO, 1999: 114). 
Isso se apresenta nos livros pertencentes ao corpus: “A comunicação é um conceito amplo e complexo que pode ser estudado das mais diferentes formas e sob a luz de diversas perspectivas teóricas. (...) Seu objeto é interdisciplinar e tem despertado um interesse crescente em diversas áreas do conhecimento" (COSTA et alli, 2006: 7).

O elemento doutrinário de cada campo funda-se sobretudo na auto-suficiência de definir quem ou o que pertence ou não pertence ao domínio epistemológico desta ciência. A classificação de um campo do saber está vinculada à possibilidade de definir uma diferença específica em relação aos outros campos, mesmo quando guarda elementos gerais em comum.

Parece que apenas a partir da metade da década de 90 o campo da comunicação se estrutura de maneira a reconhecer uma trajetória autônoma e reivindicar para si autores de outros campos que foram, pela proximidade epistemológica ou de estudos, incorporados ao debate. Como observa um dos livros que formam o corpus desta pesquisa: “A Comunicação pode ser observada como uma jurisdição teórica, no interior da qual se alinham temas e teses, comportando definições e conceitos operatórios" (TRINTA \& POLISTCHUK, 2002: 59).

Essa disparidade entre o que é ou deixa de pertencer à "teoria da comunicação", seja como disciplina, seja como campo do conhecimento, área do saber ou qual outro nome se utilize, é a parte mais externa do problema. Trata-se, na realidade, de encontrar um estatuto epistemológico claro a partir do qual seria possível identificar o princípio de uma teoria da comunicação.

\section{O objeto múltiplo}

"Uma das principais características da área tem sido uma acentuada imprecisão em relação à definição do seu objeto de estudos. Qualquer encontro entre especialistas em Comunicação nos revelará um profundo desacordo sobre questões básicas" (LIMA, 1983: 86). Nesse sentido, a discussão sobre o objeto da comunicação pode ser dividida em duas vertentes.

De um lado, os que vêem a Comunicação como um campo interdisciplinar sem objeto definido - e nisso reside sua qualidade; de outro, procura-se localizar o objeto, seja na comunicação como prática social ou nos media, de maneira restrita. Essa pluralidade leva a "questionar a necessidade de um 'local próprio' à comunicação, enquanto uma disciplina insular que seleciona uma única dimensão do real em detrimento da complexidade deste" (SANTOS, 2005: 163).

De um lado, defende-se que o objeto é múltiplo, plural, e que a característica fundante da comunicação é justamente a inexistência de um objeto único. Assim, haveria um ponto de flutuação nas concepções sobre comunicação que teriam como elemento principal a multiplicidade. "Contrariamente a uma visão que considera que a comunicação não tem um objeto, porque ou ele é amplo/estrito demais, pressupomos que a sua riqueza 
deriva-se de seu caráter inexato e complexo. (...) Sua especificidade é a de transbordar fronteiras" (SANTOS, 2006: 115).

Assim, a singularidade da comunicação seria não ter singularidade. No entanto, esse paradoxo se desfaz quando essa postura é compreendida vendo-se a comunicação como o elemento de articulação central das práticas sociais.

Note-se, a título de exemplo, a dissonância entre duas perspectivas relativas ao objeto. Afonso de Albuquerque (2002: 30) pontua a questão a partir da relação tecnológica. Moragas Spa (1997: 28), ao contrário, pensa a comunicação como processo social.

A situação talvez possa ser resumida ou simplificada no choque entre um conceito menos acabado e mais aberto sobre o que é comunicação e outro, bastante mais limitado, que parece tomar a noção de meios de comunicação de massa como elemento caracterizador essencial dos fenômenos comunicacionais (FELINTO, 2007: 43).

Martins (2005) faz uma distinção ao apontar que muitos estudos dados como pertencentes à área de comunicação na verdade destinam-se à compreensão da chamada "esfera informacional", centrada nos meios de comunicação, em contraposição a uma "esfera comunicacional”, descrita pelo autor como "dialógica e emancipatória". Mas é possível questionar, por exemplo, se não há um conceito expandido de "mídia", onde se incluiria, por exemplo, o corpo, em lugar de uma leitura "textocêntrica" da comunicação.

Isso pode ficar claro em dois exemplos retirados dos livros do corpus desta análise: em (A) José Marques de Melo propõe a definição pelo meio, enquanto em (B) Trinta e Polistchuk preconizam a análise das interações humanas:

A) o estudo sistemático de todos os meios, formas e processos de informação ou de comunicação social (MELO, 1999: 19).

B) Comunicação compõe o processo básico para a prática das relações humanas, assim como para o desenvolvimento da personalidade individual e do perfil coletivo (TRINTA \& POLISTCHUK, 2002: $62)$.

Essa indefinição do objeto remete a um problema decorrente: para um objeto múltiplo, múltiplos métodos e conceitos, múltiplas serão as análises e teorias. Por exemplo, Cooper, Potter e Dupagne (1997: 23), de um lado, e Trumb (2004), de outro listam os métodos usados nas pesquisas em comunicação. Os dois textos mostram uma oscilação constante entre métodos quantitativos, oriundos das ciências naturais, e uma abordagem qualitativo-interpretativa dos fenômenos comunicacionais.

A Teoria da Comunicação é uma área que, pela pluralidade de enfoques e objetos que comporta, torna difícil qualquer tentativa de sistematização. De inegável vocação interdisciplinar - de certo modo 
justificada pela onipresença do fenômeno comunicacional na constituição da cultura e nas práticas da vida social -, a Teoria da Comunicação pode ser entrecortada tanto pelo prisma de seus temas preferenciais quanto pelo ângulo de suas matrizes teóricas (ROCHA \& COELHO, 2004: 7).

Isso, de saída, já renova o paradoxo: por que existe uma disciplina curricular chamada "teoria da comunicação" se fazer "teoria" no campo da comunicação exige saberes oriundos de mais de uma disciplina? A idéia de ultrapassar as fronteiras serve ao mesmo tempo como pressuposto epistemológico e justificação política do campo. Sem objeto definido, só resta à comunicação se apresentar como "interdisciplinar", converter essa característica em vantagem e extrair dela o máximo de lucro simbólico, entendido como o prestígio específico na hierarquia decorrente da autonomia relativa dos campos do saber.

\section{A pluralidade interdisciplinar}

Como sugere Locker (1994), a transformação de uma área do saber em uma disciplina específica é uma maneira de aglutinar poderes e forças em torno de um grupo de discussões comuns. Assim, o conhecimento alocado sob o domínio de um método específico garante o monopólio dos discursos e das práticas derivadas ao grupo reconhecido como representante dessa disciplina ou socialmente autorizado a falar em seu nome. Os critérios de formação do saber acadêmico e a própria noção de campo como um conjunto de forças demonstram isso. Não obstante, as "disciplinas tradicionais, o modo como as universidades dividiram o conhecimento e o alocaram o poder, estão sob ataque" (LOCKER, 1994: 137). Assim, constituindo-se em um campo multidisciplinar, a Comunicação parece ter condições de assumir a vanguarda metodológica de reintegração de conhecimentos e saberes: "Portanto, é possível deduzir que a maior riqueza do "pensamento comunicacional' não esteja na caracterização de um objeto próprio, mas na sua interdisciplinaridade" (MARTINS, 2005: 5).

$\mathrm{Ou}$, dito de outra maneira:

A pesquisa em comunicação assume a natureza de um campo interdisciplinar de estudos, envolvendo não só as investigações lingüísticas, educacionais, jornalísticas, cibernéticas etc. - ou seja, as pesquisas próprias das Ciências da Informação - mas englobando também as iniciativas em outras áreas das ciências humanas - sociológicas, psicológicas, históricas, antropológicas, etc. (MELO, 1999: 20).

Ou ainda:

Mais do que uma 'interciência', o campo de estudos da comunicação se oferece como território de busca multidisciplinar, isto é, um terreno fértil para o intercâmbio teórico-metodológico que, longe de o descaracterizar, reproduz, por sua existência e sua assiduidade, a movência própria à Comunicação (TRINTA \& POLISTCHUCK, 2002: 66). 
No entanto, há duas questões relacionadas: em primeiro lugar, apesar disso a comunicação também não deixa de ser um espaço de embate entre saberes e poderes (e uma análise dessas relações não pertence ao escopo deste texto); de outro, essa mesma perspectiva esbarra em paradoxos que, aparentemente, desgastam a proposta.

Há, pois, uma extensão enorme de fenômenos associados à palavra comunicação. Isso, se por um lado, tem como aspecto positivo desqualificar a idéia de disciplinaridade, por outro lado cria uma dependência de outros saberes, o que foi historicamente um dos maiores entraves à própria autonomização do campo (BARBOSA, 2002: 74).

A idéia de interdisciplinaridade e o esforço para sua adesão, no dizer de Luiz Martino (2001: 78), é o “testemunho paradoxal tanto da sobrevivência quanto da superação de um problema que estranhamente resta pouco abordado, senão intacto: o problema da definição do objeto de estudo dessa disciplina". Na mesma linha, Everardo Rocha (1995: 54) aponta a perspectiva interdisciplinar como um "complicador transparente" nos estudos de comunicação.

O problema é de ordem lógica: pode uma ciência ter vários objetos e vários métodos? Em última instância, uma ciência da comunicação implode o conceito tradicional de ciência. Não é aqui o lugar de discutir a validade ou não da idéia segunda a qual a comunicação é um campo interdisciplinar, mas pensá-la como sendo a representação hegemônica do campo encontrada na bibliografia corrente - com exceções, é claro. São poucos os esforços de conceituação ou definição metodológica dos conceitos utilizados no campo - fazer “teoria” não seria apenas enquadrar conceitos (CAMPBELL, 2003: 505).

Não se trata, em primeira instância, de condenar ou defender o cruzamento entre disciplinas, mas fazer um balanço, similar ao que faz Locker (1994: 139) em um artigo intitulado "Os desafios da pesquisa interdisciplinar”. Após argumentar que a interdisciplinaridade enfraquece o campo da comunicação, aponta no mesmo texto que "idéias e descobertas de outros campos podem nos auxiliar a ver o que conhecemos sob uma nova ótica, colocando o conhecimento sob nova perspectiva que pode ser maior - ou diferente - do que seria visto na forma original" (LOCKER, 1994: 143).

É possível questionar se o fato de um mesmo objeto ser estudado por diversas ciências o torna interdisciplinar (Martino, 2005: 46). A pluralidade de aspectos de um fenômeno permite seu estudo por qualquer ciência. Não é isso, portanto, que justificaria uma abordagem para além de uma única disciplina. A tabela a seguir indica alguns desses elementos referentes às ambivalências apontadas: 


\begin{tabular}{|c|c|c|c|c|}
\hline & $\begin{array}{l}\text { Definição de } \\
\text { comunicação }\end{array}$ & $\begin{array}{l}\text { Objeto de } \\
\text { estudos da } \\
\text { comunicação }\end{array}$ & $\begin{array}{l}\text { Métodos/disciplinas } \\
\text { de estudo }\end{array}$ & $\begin{array}{l}\text { O que é Teoria } \\
\text { da } \\
\text { Comunicação }\end{array}$ \\
\hline $\begin{array}{c}\text { Tópicos de } \\
\text { teoria da } \\
\text { comunicação, } \\
\text { Pedro Gilberto } \\
\text { Gomes }\end{array}$ & $\begin{array}{c}\text { Interação } \\
\text { humana - } \\
\text { fenômeno social }\end{array}$ & $\begin{array}{c}\text { Estudar a } \\
\text { interação } \\
\text { humana midiada }\end{array}$ & Plural & $\begin{array}{l}\text { Estudo dos } \\
\text { processos de } \\
\text { interação } \\
\text { humana }\end{array}$ \\
\hline $\begin{array}{c}\text { Teorias da } \\
\text { comunicação na } \\
\text { América } \\
\text { Latina>, Costa } \\
\text { et alli } \\
\end{array}$ & Não define & Não define & Interdisciplinar & Não define \\
\hline $\begin{array}{c}\text { Teoria da } \\
\text { Comunicação, } \\
\text { José Marques } \\
\text { de Melo }\end{array}$ & $\begin{array}{c}\text { Opta por } \\
\text { "informação" } \\
\text { para definir a } \\
\text { interação } \\
\text { midiada entre } \\
\text { indivíduos }\end{array}$ & $\begin{array}{c}\text { interação } \\
\text { humana que } \\
\text { acontece na } \\
\text { circulação de } \\
\text { informações, } \\
\text { incluíndo meios } \\
\text { técnicos } \\
\end{array}$ & Interdisciplinar & $\begin{array}{l}\text { Prefere teoria da } \\
\text { informação para } \\
\text { definir o estudo }\end{array}$ \\
\hline $\begin{array}{c}\text { As teorias da } \\
\text { comunicação, } \\
\text { Roberto Elísio } \\
\text { dos Santos }\end{array}$ & $\begin{array}{l}\text { Interação } \\
\text { humana }\end{array}$ & $\begin{array}{l}\text { As interações } \\
\text { entre seres } \\
\text { humanos }\end{array}$ & Interdisciplinar & $\begin{array}{l}\text { Estudo dos } \\
\text { processos de } \\
\text { interação } \\
\text { humana em } \\
\text { sentido amplo }\end{array}$ \\
\hline $\begin{array}{c}\text { Teorias da } \\
\text { Comunicação, } \\
\text { Antonio Hohfeldt } \\
\text { et alli }\end{array}$ & $\begin{array}{l}\text { Discussão do } \\
\text { tema }\end{array}$ & $\begin{array}{l}\text { Discussão do } \\
\text { tema }\end{array}$ & Discussão do tema & $\begin{array}{l}\text { Discussão do } \\
\text { tema }\end{array}$ \\
\hline $\begin{array}{l}\text { Introdução à } \\
\text { teoria da } \\
\text { comunicação, } \\
\text { Francisco } \\
\text { Rüdiger }\end{array}$ & $\begin{array}{c}\text { Interação } \\
\text { humana - } \\
\text { fenômeno social }\end{array}$ & $\begin{array}{c}\text { Interação } \\
\text { humana midiada }\end{array}$ & $\begin{array}{c}\text { Plural / } \\
\text { Interdisciplinar }\end{array}$ & $\begin{array}{l}\text { Estudo dos } \\
\text { processos de } \\
\text { interação } \\
\text { humana }\end{array}$ \\
\hline $\begin{array}{c}\text { Teorias da } \\
\text { Comunicação, } \\
\text { Luiz Martins }\end{array}$ & Não define & Meios técnicos & $\begin{array}{l}\text { Plural / Vinculado à } \\
\text { outras disciplinas ou } \\
\text { ao elemento técnico }\end{array}$ & $\begin{array}{c}\text { Estudo dos } \\
\text { meios técnicos } \\
\text { de comunicação }\end{array}$ \\
\hline $\begin{array}{c}\text { Teorias da } \\
\text { Comunicação, } \\
\text { Ilana Politschuk } \\
\text { e Aloízio R. } \\
\text { Trinta }\end{array}$ & $\begin{array}{l}\text { Interação } \\
\text { humana; } \\
\text { processo de } \\
\text { construção } \\
\text { simbólica }\end{array}$ & $\begin{array}{l}\text { Interação } \\
\text { humana }\end{array}$ & Interdisciplijnnar & $\begin{array}{c}\text { Estudo das } \\
\text { interações } \\
\text { humanas } \\
\text { mediadas }\end{array}$ \\
\hline $\begin{array}{c}\text { Teoria da } \\
\text { Comunicação, } \\
\text { Rodrigo Vilalba }\end{array}$ & $\begin{array}{l}\text { Processo } \\
\text { sbimólico }\end{array}$ & $\begin{array}{l}\text { Relações } \\
\text { humanas }\end{array}$ & Interdiscilpinar & $\begin{array}{l}\text { Estudo das } \\
\text { relações } \\
\text { humanas }\end{array}$ \\
\hline $\begin{array}{c}\text { Teoria da } \\
\text { Comunicação na } \\
\text { América Latina, } \\
\text { Alberto Efendy } \\
\text { Maldonado }\end{array}$ & Não define & Não define & $\begin{array}{l}\text { Interdisciplinar / } \\
\text { Transdisciplinar }\end{array}$ & Não define \\
\hline
\end{tabular}




\section{Indefinições finais}

O problema da ausência de uma definição tem uma consequência na prática acadêmica: qual fronteira decide o que é um trabalho de comunicação? Na hora de solicitar um auxílio de pesquisa ou submeter um texto para avaliação, qual é o critério para classificá-lo entre os estudos de comunicação? Afinal, "boa parte daquilo que se publica em nossos periódicos de comunicação poderia, sem grandes dificuldades, ser catalogado dentro da área dos cultural studies" (FELINTO, 2007: 45).

Outros autores apontam essa indefinição no aparecimento de uma área independente chamada "teoria", que ocupa um vasto espaço nas Ciências Humanas sem especificamente pertencer a nenhum (EAGLETON, 1987; CULLER, 2007; VENN, 2007) ou, como Santaella (2001: 15) recorda, sobre a atividade em uma agência de fomento à pesquisa, a lista de disciplinas e campos relacionados à comunicação "mais se parecia a uma enumeração caótica". E conclui: "muitas vezes, tínhamos que julgar projetos, nitidamente interdisciplinares, que suscitavam fortes dúvidas quanto à sua inserção ou não na área de comunicação".

Não poderia ser de outra maneira. Se o campo é interdisciplinar, se não tem objeto próprio, se não tem metodologia própria, os critérios de análise e avaliação da pertinência a esse campo do saber parecem ser extremamente fluidos. O resultado é a crença compartilhada - o que Bourdieu chamaria de illusio - na interdisciplinaridade como marco de distinção das pesquisas deste campo (BARROS FILHO \& MARTINO, 2003: 160).

O objeto não é definido, o método tampouco. Os métodos de análise são igualmente importados de outras ciências - etnografias da audiência ou de produção, análises estruturais da mensagem, teorias políticas, de recepção, de percepção (HARDT, 1999). Uma alternativa epistemológica é a percepção dos atos comunicativos como elementos articuladores centrais das relações humanas - e isso talvez elimine a multiplicidade do objeto afirmando o processo, não o modo, a partir do qual a prática será explicada (MARCONDES FILHO, 2005; MARTINO, L. C. 2007: 8; MARTINO, L. M., 2007: 10).

A questão permanece em aberto. Afinal, "a emergência de um campo de conhecimento abrange, assim, uma rede epistemológica marcada por zonas de consenso, conflito e negociações" (FERREIRA, 2003: 118). Seja olhando as questões relativas à Teoria da Comunicação em seus eixos internos (objeto, método, epistemologia) ou externos, como um campo de forças em conflito no qual agentes buscam uma definição legítima das práticas e saberes, os cursos e disciplinas de comunicação permanecem no diálogo aberto - para ter algo a dizer aos 40 mil alunos de Comunicação formados anualmente.

\section{Notas}

Uma versão prévia deste texto foi apresentado no GP Teorias da Comunicação durante o XXXII Congresso Brasileiro de Ciências da Comunicação. Curitiba (03-07/09/2009). 


\section{Referências bibliográficas}

BARBOSA, M. "Paradigmas de construção do campo comunicacional". In: Hohfeld, A. et alli. Tensões e Objetos da Pesquisa em Comunicação. Porto Alegre: Sulina, 2002.

BARROS FILHO, C. e MARTINO, L. M. S. O habitus na comunicação. São Paulo: Paulus, 2003.

BELTRÁN, L. R. “Adeus a Aristóteles: comunicação horizontal”. In: Comunicação e Sociedade, n. 6. São Paulo: Cortez/Intercom, 1981.

BRYANT, J. \& MIRON, D. "Theory and Research in Mass Communication”. In: Journal of Communication. December 2004/Vol. 54, n. 4.

CAMPBELL, J. “Theory after the PostModern Condition”. In: Organization. 2003.

COSTA, R. et alli. Teoria da Comunicação na América Latina. Curitiba: UFPR, 2006.

CULLER, J. Literary Theory. Oxford: Oxford University Press, 2007.

DAHLGREN, P. "Theory, Boundaries and Political Communication". In: European Journal of Communication 2004.

EAGLETON, T. Literary Theory. Londres: Verso, 1987.

ECO, U. Apocalipticos e Integrados. São Paulo: Perspectiva, 2001.

FELINTO, E. "Patologias no sistema da comunicação: ou o que fazer quando seu objeto desaparece". In: FERREIRA, G. e MARTINO, L. C. Teorias da Comunicação. Salvador: UFBA, 2007.

FERREIRA, J. “Campo acadêmico e epistemologia da comunicação”. In: LEMOS, A. et alli (orgs). Mídia.br. Porto Alegre: Sulina, 2003.

FRANÇA, V. R. V. "Representações, mediações e práticas comunicativas". In: PEREIRA, M. et alli. Comunicação, representação e práticas sociais. Rio de Janeiro: Idéias e Letras/PUC-RJ, 2004.

FUENTES NAVARRO, R. "La investigación de la comunicación en América Latina”. In: Comunicación y Sociedad, n.36. Guadalajara: Universidad de Guadalajara, 1999.

GORDON, R. "Beyond the Failures of Western Communication Theory”. In: Journal of Multicultural Studies, 2 (2), 2007, p. 89-107.

HARDT, H. "Shifiting paradigms: descentring the discourse of mass communication research". In: Mass Communication quarterly, 1999.

HABERMAS, J. "The analytic theory of science and dialects". In: ADORNO, T. W. et alli. The positivist dispute in german sociology. Londres: Heineman, 1976.

HEISLER, J. \& DISCENNA, T. "Teaching Metatheoretical Beliefs in Communication Theory". In: Communication Teacher.

LIMA, V. "Profissões e formação teórica em comunicação”. In: Intercom, n. 62/63, 1991. . "Repensando as teorias da comunicação”. In: MELO, J. M. Teoria e pesquisa em comunicação. São Paulo: Intercom/Cortez, 1983. 
LOCKER, K. "The Challenge of Interdisciplinary Research". In: Journal of Business Communication, n. 31, 1994.

MALDONADO, A. “América Latina berço de transformação comunicacional no mundo”. In: MELO, J. M. e GOBBI, M. C. Pensamento Comunicacional Latino-Americano. São Bernardo do Campo: Metodista, 2004.

MARCONDES FILHO, C. “Apresentação”. In: LUHMANN, N. A realidade dos meios de comunicação. São Paulo: Paulus, 2005.

MARTINO, L. C. “Apontamentos epistemológicos sobre a fundação e a fundamentação do campo comunicacional”. In: CAPPARELLI, S. et alli. A Comunicação Revisitada. Porto Alegre: Sulina, 2005.

. "Interdisciplinaridade e Objeto de Estudos da Comunicação". In. FAUSTO NETO, A. et alli. $O$ Campo da Comunicação. João Pessoa: UFPB, 2001. . Teorias da Comunicação: muitas ou poucas?. Cotia: Ateliê, 2007.

MARTINO, L. M. Comunicação: troca cultural. São Paulo: Paulus, 2005. . Estética da Comunicação. Petrópolis: Vozes, 2007. . “A ilusão teórica no campo da comunicação". In: Famecos, n.38. Porto Alegre, 2008.

MARTINS, L. Teorias da comunicação no século XX. Brasília: Casa das Musas, 2005.

MELO, J. M. "Introdução”. In: MELO, J. M. e BRANCO, S. C. Pensamento Comunicacional Brasileiro. São Bernardo do Campo: Universidade Metodista, 1999.

DEMERS, D. "Communication Theory in the 21st Century: Differentiation and Convergence". In: Mass Communication and Society, 2000.

MIIKE, Y. “Asian Contributions to Communication Theory”. In: Media Research, 3(4), 2007.

MORAGAS, M. “Las ciencias de la comunicación en la 'sociedad de la información"”. In: Revista Dia-Logos de la Comunicación, n. 49, 1997.

OLSEN, S. “The moment of theory”. In: Critical Quarterly, n. 4, 2007.

MORSE, J. “Theory innocent of Theory Smart”. In: Quality Health Research, 2002.

ROACH, C. "Cultural imperialism and resistance in media theory". In: Media Culture Society, 1997.

ROCHA, E. A sociedade do sonho. Rio de Janeiro: Mauad, 1995. 